Res Publica. Revista de Historia de las Ideas Políticas ISSN: 1576-4184

http://dx.doi.org/10.5209/RPUB.54995

\title{
Observaciones acerca del concepto hegeliano de "privilegio"
}

\author{
Damián Jorge Rosanovich*
}

Recibido: 11 de junio 2015 / Aceptado: 21 de octubre 2016

Resumen. El objetivo de este trabajo es demostrar que Hegel alcanza a superar la oposición entre los privilegios estamentales y el poder del monarca a través de una redefinición del concepto de "privilegio". A tal fin, hacemos un recorrido por (I) el contexto del debate sobre este tópico, (II) las posiciones rechazadas por Hegel y (III) su relectura del concepto de "privilegio" a través del Estado ético.

Palabras clave: privilegio; estamento; corporaciones; revolución.

\section{[en] Remarks on the Hegelian Concept of "Privilege"}

\begin{abstract}
This paper discusses how Hegel manages to overcome the dichotomy between class (ständisch) privileges and power of the monarch by redefining the concept of "privilege". In order to demonstrate this, we briefly set forth (I) the context of the discussion about this topic, (II) Hegel's criticism of the forementioned theories, and (III) his reinterpretation of the concept of "privilege" through the theory of ethical State.
\end{abstract}

Keywords: privilege; class; corporations; revolution.

A través de diversas perspectivas es posible reconocer en la filosofía política hegeliana una doctrina específica que se opone a distintos núcleos conceptuales tanto del iusnaturalismo moderno, de Hobbes a Fichte, como de la tradición de la cameralística o de la ciencia jurídica alemana del siglo XVIII, de Wolff a Thomasius. Efectivamente, Hegel interviene con frecuencia en debates políticos de su propio horizonte contemporáneo, entre los cuales es posible destacar las disputas en torno a la Revolución Francesa en sus primeros años, la expansión de Napoleón luego de la Campaña de Italia de 1796-1797, la conformación del Estado alemán luego de la caída del Imperio, en 1806, la legitimidad del derecho electoral inglés o las discusiones en torno a la sanción de la constitución de Württemberg, en 1815-1816. A lo largo de las controversias filosóficas y de la intervención en la vida política de su tiempo, Hegel modela y precisa conceptos clave que serán expuestos en su Filosofía del Derecho de 1821, texto que ofrece la elaboración más sistemática de su doctrina política, la cual puede encontrarse tanto en escritos anteriores (la primera edición de la Enciclopedia de las ciencias filosóficas, de 1817, o el Artículo sobre el derecho

\footnotetext{
* Universidad de Buenos Aires, Argentina

d_rosanovich@yahoo.com.ar
} 
natural, de 1803) como en las Lecciones de Filosofía del Derecho que dicta entre 1817 y 1825 , en Heidelberg y en Berlín.

Lo específico de la teoría hegeliana da cuenta de la elaboración y exposición de un conjunto de conceptos que aspiran a distanciarse de la tradición filosófico-política inmediatamente precedente, y que busca superarla a través de la proposición de un nuevo aparato conceptual que pueda dar cuenta de la problematicidad del horizonte contemporáneo en el cual Hegel escribe. De esta manera, más allá de su valoración de la Revolución Francesa, Hegel aspira a clarificar los fundamentos de un orden estatal que pueda alcanzar las exigencias que imponen los conflictos políticos modernos, a los efectos de evitar la vía revolucionaria para transformar las instituciones políticas. Tanto en el debate filosófico como en el devenir de los acontecimientos de su época, uno de los conflictos que se plantean se cristaliza en torno a la lucha de poder por los privilegios estamentales, protagonizada por la asamblea de estamentos y la figura del monarca, debate que Hegel recupera (i) de la Francia prerrevolucionaria, (ii) de las discusiones en torno al código civil prusiano (el Allgemeines Landrecht für die Preußischen Staaten, de 1794), y (iii) de los debates sobre la sanción de la constitución de Württemberg, en 1815 y 1816. De modo esquemático, las posiciones a favor y en contra de dichas leges speciales pueden entenderse del siguiente modo: (a) los privilegios estamentales deben ser defendidos, ya que su fundamento es (a.1) el bien común, (a.2) la posibilidad de restringir el poder arbitrario del monarca, y (a.3) permiten diferenciar cada uno de los órdenes de la sociedad, de acuerdo a su status y a su función. Por el contrario, (b) quienes rechazan estos privilegios sostendrán que, a través de ellos, los estamentos (b.1) sólo buscan preservar sus intereses privados, (b.2) impiden la unidad del Estado, (b.3) carecen de todo tipo de control, lo cual los pone por afuera del Estado.

En nuestro trabajo nos interesa demostrar la siguiente tesis: Hegel logra superar el conflicto tardofeudal entre el monarca y la asamblea de estamentos a través de una redefinición del concepto de "privilegio" (Privileg) que le permitirá resolver esta oposición al interior del Estado orgánico, en particular, a través de la idea de una estatalidad ética. Así, Hegel expondrá una manera egoísta y antiestatal de comprender los privilegios, y un modo correcto y virtuoso de articular esta noción al interior del orden político. A lo largo de las siguientes páginas haremos una sucinta exposición del debate histórico en el cual interviene Hegel (II), para luego presentar la posición criticada por el filósofo de Stuttgart (III), y su reinterpretación de dicho tópico (IV). Por último, a modo de conclusión (V), retomaremos los aspectos más relevantes de nuestro trabajo.

\section{II}

Como han señalado numerosos intérpretes, el contexto en el cual Hegel debate acerca de los privilegios estamentales presupone la ausencia de un concepto moderno de constitución, es decir, la idea de un documento respecto del cual toda legislación ulterior debe ordenarse jerárquicamente'. En este sentido, los códigos

Para citar un ejemplo relevante para el contexto, puede recordarse el art. 16 de la Declaración de los Derechos del Hombre: "Toda sociedad en la cual la garantía de derechos no esté asegurada, ni tampoco esté determinada la separación de poderes, no tendrá una constitución", "Déclaration des droits de l'homme et du citoyen", en Les 
de fines del siglo XVIII y principios del siglo XIX (el Allgemeines Gesetzbuch austríaco o el Código Civil francés de 1804) no son constituciones strictu sensu ya que no sólo no cumplen con este requisito sino que tampoco establecen una clara distinción entre diferentes ámbitos de competencia del derecho. Entre los diversos ejemplos que Hegel conoce, tal vez el Allgemeines Landrecht ${ }^{2}$ sea el más ambicioso, puesto que combina elementos de derecho privado, comercial, eclesiástico, penal, administrativo, civil, etc. En este sentido, los así llamados privilegios estamentales no aparecen en estos documentos como una nómina de derechos fundamentales o un conjunto de leyes elementales, sino que se presentan de manera yuxtapuesta con otros derechos o excepciones que deben ser garantizadas para una parte especial de la ciudadanía. Existen diferentes taxonomías en torno a los numerosos tipos de "privilegios"3, las cuales clasifican estas leges speciales bajo diversos criterios. Entre ellas, consideramos la de Heinz Mohnhaupt como la más acertada. Intentando sintetizar el debate presente en el siglo XVIII y en el XIX, el jurista alemán diferencia entre cinco tipos de privilegios ${ }^{4}$ :

a. Prerrogativas relacionadas con el otorgamiento (Verleihung) de un derecho a un estamento específico. Éste poseerá así privilegios relacionados, por ejemplo, con regalías aduaneras o ingresos por impuestos especiales que le corresponderán con exclusividad.

b. Derechos especiales entendidos como una excepción: estamentos particulares son liberados (befreit) de la obligación de cumplir con deberes impositivos o leyes en general (exenciones impositivas, casos de inmunidad).

c. Privilegios entendidos como una "protección" (Schutz) de derechos: distintos estamentos poseen derechos especiales de segundo orden para garantizar el cumplimiento de los derechos ordinarios, en los casos en los cuales, por razones de diversa índole, su vigencia se viera en peligro.

déclarations des droits de l'homme (Du Débat 1789-1793 au Préambule de 1946), editado por L. Jaume, Paris, Flammarion, 1989, pp. 9-16, aquí p. 16. A excepción de que se señale lo contrario, todas las traducciones son nuestras. Si bien Hegel expone explícitamente el carácter crítico de los estamentos en el proyecto de constitución de Württemberg, en rigor, la referencia fundamental para este debate está presente en el Código Civil prusiano. Por tanto, por su relevancia histórica, nos referiremos a ciertos aspectos de la cuestión de los privilegios estamentales tal como son presentados allí. Cfr. C. Cesa, "L`atteggiamento politico di Hegel nel 1817: lo scritto sulla dieta del Württemberg", en Hegel filosofo político, Napoli, Guida Editori, 1976, pp. 105-143; F. Wieacker, Privatrechtsgeschichte der Neuzeit unter besonderer Berücksichtigung der deutschen Entwicklung, Göttingen, Vandenhoeck \& Ruprecht, 1967, cap. 19.

2 El Allgemeines Landrecht, sancionado finalmente en 1794, tiene dos publicaciones parciales preexistentes, en 1788 y en 1791, así como cuenta con bosquejos de la década de 1750. Naturalmente, sólo podemos referirnos a algunos aspectos del mismo aquí. Para un comentario y análisis de sus fundamentos filosóficos, históricos y políticos, véase H. Conrad, Die geistigen Grundlagen des Allgemeinen Landrechts für die Preußischen Staaten von 1794, Köln, Westdeutscher Verlag, 1958; R. Koselleck, Preußen, zwischen Reform und Revolution: Allgemeines Landrecht, Verwaltung und soziale Bewegung von 1791 bis 1848, München, Klett-Cotta, 1967; D. Canale, Le costituzione delle differenze. Giusnaturalismo e codificazione del diritto civile nella Prussia del '700, Torino, Giappichelli Editore, 2000; M. Hernández Marcos, "Conoscenza razionale e storia. Sulla relazione tra diritto naturale e diritto positivo nella codificazione prussiana del 1794“, en L. Fonnesu, L. y B. Henry (eds.), Diritto naturale e filosofia classica tedesca, Pisa, Pacini, 2000, pp. 39-54.

3 Entre las proposiciones clásicas, cabe mencionar los artículos: "Privilège", en Encyclopédie, ou Dictionnaire raisonné des sciences, des arts et des métiers, editado por Diderot y D Alembert, Genève, 1778; y "Privilegium", por J. Pözl, en Deutsches Staats-Wörterbuch, editado por J. C. Bluntschli y K. Brater, Stuttgart / Leipzig, 1864, s/d.

4 Cfr. H. Mohnhaupt, "Untersuchungen zum Verhältnis Privilegien und Kodifikation im 18. und 19. Jahrhundert", en Ius Commune, V, 1975, pp. 71-121, aquí p. 84 y ss. 
d. Concesiones interpretables bajo el silencio de la ley: dado un estamento que posea un privilegio en especial, al ostentar un status superior (valga la aclaración, respecto de una cuestión en particular), habrá de invocar como naturales privilegios no escritos que pudieran deducirse de otros privilegios ya escritos.

e. Por último, las prerrogativas entendidas como derechos especiales (Sonderrechte): dada la ausencia de un ordenamiento jurídico jerárquicamente organizado, en ciertas ocasiones el príncipe debe respetar los contratos especiales entre privados con los dueños de las tierras, en los cuales se establecían consideraciones específicas acerca del pago de impuestos.

Los privilegios estamentales aparecen con frecuencia en el contexto alemán, puesto que la organización jurídica estamental obedece a una tradición que puede hallarse en distintos reinos. A los efectos de señalar aquello que es de relevancia para Hegel, es posible mencionar el caso del Allgemeines Landrecht prusiano y el citado proyecto de constitución de Württemberg ${ }^{5}$. Es preciso aclarar que el Landrecht, si bien es sancionado hacia 1794, en el contexto de una fuerte discusión acerca de las proyecciones de la Revolución Francesa (entre otras cosas, luego de la sanción de la Constitución de 1791), es el resultado de diferentes proyectos constitucionales federicianos, el primero de los cuales, cuando menos, debe situarse en el Bosquejo de Cocceji, de 1749-1751. Es por este motivo que Hegel, entre otros contemporáneos suyos, considera de escasa o nula relevancia debatir acerca de la actualidad política del mismo. Con todo, es preciso señalar que el Landrecht ofrece distintos elementos que, de manera ejemplar, pueden ser señalados como constitutivos del horizonte de discusión que, como veremos, presupone el contexto del debate de Württemberg.

De este modo, es menester poner en evidencia algunos rasgos fundamentales de la cuestión de los privilegios estamentales, tal como aparecen en el Landrecht, a los efectos de poder comprender las críticas de Hegel a esta institución. Ante todo, es relevante señalar que la ausencia del carácter constitucional (en el sentido precisado) obedece al señalamiento de un orden alternativo, el cual presenta de manera yuxtapuesta una organización de la sociedad articulada en torno a estamentos (v. g. un individuo goza de determinado conjunto de derechos por pertenecer a un estamento específico, y no en su carácter de persona), pero también a individuos. Canale sostiene: "Esta anomalía estructural, demasiado singular a los ojos del observador contemporáneo, ha señalado el destino infausto del código prusiano en la historia de sus interpretaciones. El carácter anfibio de sus contenidos -todavía ligados al equilibrio del particularismo jurídico y de la sociedad estamental, pero también cercano a los sistemas del iusnaturalismo moderno y al Estado de derecho- ha hecho de él un Jano bifronte" .

En este sentido, cabe agregar que el Código no sólo no presupone una nítida distinción entre derecho público y derecho privado, sino que tampoco presenta una división entre sociedad civil y Estado 7 . Asimismo, el Código ofrece una organiza-

\footnotetext{
Es preciso aclarar que no se aspira en este trabajo a hacer una presentación exhaustiva del trasfondo histórico de la cuestión de los privilegios, sino sólo de aquello que es relevante para comprender la crítica hegeliana a los mismos.

6 Cfr. D. Canale, La costituzione delle differenze..., op. cit., p. 13.

7 M. Riedel ha desarrollado la tesis según la cual Hegel sería el primer filósofo en distinguir con discreción los conceptos de sociedad civil (bürgerliche Gesellschaft) y Estado (Staat), mientras que, hasta ese entonces, éstos
} 
ción estamental del orden político con privilegios estamentales y derechos especiales (Sonderrechte), los cuales coexisten con una declamada "igualdad ante la ley" de todos los ciudadanos. De manera concomitante, cabe señalar que este Gesetzbuch halla su estatuto de código no en la moderna intelección de un conjunto de derechos fundamentales consagrados en normas a ser respetadas por toda legislación ulterior, sino en una concepción híbrida compuesta a la vez por derechos individuales y estamentales ${ }^{8}$; y en la idea de un elemento constituyente articulador del orden político, cercano al desarrollo de las Ciencias Camerales en Alemania a lo largo del siglo XVIII, en particular, a la evolución de una tratadística destinada a fundamentar teóricamente la estructura organizativa y funcional de la administración pública.

El carácter híbrido de la estructura del Allgemeines Landrecht se hace visible en el ejercicio de los derechos civiles, los cuales proceden tanto de la condición atómica de cada persona individual como de su pertenencia a un estamento, la cual implica la introducción del individuo en un conjunto de relaciones que habrán de otorgarle capacidades específicas para gozar de ciertos derechos. Así, tales capacidades dependen lógicamente de la condición de miembro de dicho estamento. En este sentido, es posible leer artículos que, al interior de la sociedad, oscilan pendularmente entre la dimensión individual y la consocial: "El hombre se define como persona [Person] en cuanto disfruta de ciertos derechos en la sociedad civil [bürgerlichen Gesellschaft]"; 9 o "Los derechos universales del hombre se fundan en la libertad natural del hombre, y en la posibilidad de perseguir y promover [befördern] el propio bienestar [Wohl] sin lesionar los derechos de los otros". ${ }^{10}$ Estos dos artículos señalan la referencia individual del sujeto de derecho, a quien ulteriormente se le concederán derechos específicos.

Ahora bien, en el Allgemeines Landrecht es posible leer también: "Los derechos y deberes particulares de los miembros del Estado [Staat] se basan [beruhen] en las relaciones personales [persönliche Verhältnisse] en las cuales cada uno se encuentra respecto de los otros y frente al Estado". ${ }^{11}$ De modo semejante, el Código también indica que la sociedad civil no se compone de meros individuos, sino de "una pluralidad de sociedades [Gesellschaften] y estamentos [Stände] más pequeños". ${ }^{12}$ Esta diferencia estamental permite observar que la igualdad de origen frente al derecho sufre una metamorfosis a través de la asignación de una idoneidad jurídica lógicamente dependiente de la pertenencia a un estamento en particular. Como señala D. Canale: "Junto a la igualdad formal de la persona universal, corresponde a una igual

vocablos habrían sido utilizados como sinónimos. Cfr. M. Riedel, "Tradition und Revolution in Hegels "Philosophie des Rechts"““, en Zwischen Tradition und Revolution. Studien zu Hegels Rechtsphilosophie, Stuttgart, Klett-Cotta, 1982, pp. 170-222, aquí p. 182 y ss. Para un estudio histórico de la idea de sociedad civil, véase la reciente publicación: M. Riedel, Bürgerliche Gesellschaft. Eine Kategorie der klassischen Politik und des modernen Naturrechts, Stuttgart, Steiner, 2011, pp. 239-338.

8 Wieacker sitúa la fuente de esta conjunción de elementos heterogéneos en la convergencia entre el iusnaturalismo de C. Wolff y el de S. Pufendorf. Cfr. F. Wieacker, Privatrechtsgeschichte der Neuzeit..., op. cit., cap. 19, § 3; A. Schwennicke, por su parte, directamente tipifica como contradictorio el solapamiento entre planos individuales y estamentales, así como entre igualdad ante la ley y la concesión de privilegios. Cfr. A. Schwennicke, Die Entstehung der Einleitung des Preußischen Allgemeinen Landrechts von 1794, Frankfurt am Main, Vittorio Klostermann, 1993, p. 8 y ss.

9 Allgemeines Landrecht für die Preußischen Staaten von 1794 [Con un estudio preliminar de H. Hattenhauer y una bibliografía de G. Bernert], Neuwied / Berlin, Luchterhand, 1996, I, 1, §1.

$10 \quad$ Ibidem, $\$ 83$.

$11 \quad$ Ibidem, $\S 84$.

12 Ibidem, I, $1, \S 2$. 
idoneidad el hecho de ser titular de derechos y deberes. Se despliega, por tanto, la desigualdad sustancial entre personas particulares, entendida como expresión de los estamentos y de las consociaciones, en base a criterios de pertenencia fijados por la ley"13.

El elemento particularmente controversial del Allgemeines Landrecht constituye lo que R. Koselleck ha llamado su "rostro de Jano"14, dado que confluyen en él momentos de una estatalidad moderna con componentes estamentales que, a través de distintos procedimientos, habrán de oponer resistencia a la buscada modernización del derecho civil. Con otras palabras, en el Código Civil prusiano coexiste la igualdad de los ciudadanos ante la ley con "privilegios [Privilegien]" estamentales que constituyen excepciones a esta misma ${ }^{15}$. De esta manera, queda cristalizada aquí una doble yuxtaposición, que será particularmente reinterpretada por Hegel, a saber: en primer lugar, el solapamiento entre un ordenamiento jurídico a través de individuos iguales ante la ley, que habrán de gozar o carecer de ciertos privilegios por la estricta pertenencia a un estamento. En segundo lugar, de manera concomitante, la asimetría en la titularidad de derechos dada en virtud de que no todos los estamentos habrán de gozar de los mismos, sino que, de acuerdo con el sujeto y con el objeto, tendrán lugar prerrogativas a los fines de favorecer a determinados grupos sociales ${ }^{16}$.

Como ha expresado H. Mohnhaupt: "El Allgemeines Landrecht garantizó la igualdad formal ante la ley, pero no creó una igualdad material abarcativa a través de la ley" ${ }^{17}$. Este rasgo del Código no es difícil de comprender, si se piensa que, para muchas de las teorías jurídicas y latu sensu fuentes filosóficas del mismo (v. g. la doctrina wolffiana), el representante que gobierna se refiere siempre a una organización social estamental preexistente, motivo por el cual la representación no es, como para Hobbes, la instancia formante en la cual se produce la unidad del pueblo, dado que no hay pueblo sin representante, sino que esta representación debe dar cuenta forzosamente de un orden homogéneamente ya constituido ${ }^{18}$. Así, bajo esta tradición no es ilógico pensar que tal igualdad ante la ley no presuponga desigualdades estamentales de origen que, ni en su letra ni en su espíritu, aspiren a ser superadas. En la

13 D. Canale, La costituzione delle differenze..., op. cit., p. 244.

14 R. Koselleck, Preußen zwischen Reform und Revolution, op. cit., p. 24 y ss.

15 Según la tesis de Koselleck, el sujeto de derecho presupuesto en el Allgemeines Landrecht no es uniforme ni del todo claro a causa de las tensiones internas en torno a los derechos especiales de los estamentos. Según él: "El Landrecht no conoció ciudadanía alguna. En lugar de esto, aparecen en él distintos conceptos que a lo largo del Vormärz fueron reformulados", Ibidem, pp. 660-661.

16 Lamentablemente, carecemos del espacio para llevar a cabo un análisis exhaustivo del régimen de derechos especiales. Con todo, allende la tipificación de los privilegios estamentales, el Código es hondamente explícito en referencia a las prerrogativas (Vorrechte), por ejemplo, de la nobleza. Cfr. Allgemeines Landrecht, op cit., II, 9, $§ 1$ (condición de primer estamento del Estado); II, 9, §§ 34-50 (capacidades); II, 9, §§ 52-58 (posesión de bienes).

17 Como señalan los estudios de H. Mohnhaupt, es interesante destacar que esta condición no sea pensada como incompatible o contradictoria, tanto en lo concerniente a los vínculos entre individuos como en lo referido a la relación entre los estamentos y el Estado. Cfr. H. Mohnhaupt, "Privilegien und "gemeines Wohl» im ALR sowie deren Behandlung durch die Theorie und Praxis im 19. Jahrhundert", en B. Dölemeyer y H. Mohnahupt (eds.), 200 Jahre Allgemeines Landrecht für die Preußischen Staaten: Wirkungsgeschichte und internationaller Kontext, Frankfurt am Main, Klostermann, 1995, pp. 105-144, aquí p. 112.

18 Cfr. Acerca de la homogeneidad del elemento previo a la representación en esta tradición, véase G. Duso, $L a$ rappresentanza politica. Genesi e crisi del concetto, Milano, Franco Angeli, 2003, pp. 59-77. Asimismo, como sostiene Duso "la división en estamentos es peligrosa para la libertad, pues aquí puede darse un espíritu de cuerpo que se ponga rápidamente contra el espíritu del todo", Libertà e costituzione in Hegel, Milano, Franco Angeli, 2013, p. 33. 
tradición hobbesiana, por el contrario, la representación da forma a un pueblo cuya existencia prepactista no puede ser reivindicada por los individuos. Esto se debe a que, por una parte, no existe el pueblo antes del pacto, y por otra, a que las acciones que el soberano lleva a cabo no pueden ser desconocidas por los súbditos, ya que éstos son los autores de las mismas.

Por último, hay que señalar que la relación de Hegel con el Allgemeines Landrecht no es explícita. No se encuentran referencias a él en sus textos publicados, y en su obra no publicada son considerablemente discutibles las citas oblicuas ${ }^{19}$. Además, Hegel no cita a Svarez, teórico y redactor del Código, y cuando menciona a Klein no lo hace en su calidad de jurista interviniente en la redacción del Código, sino por ser uno de los penalistas más importantes de Prusia a fines del siglo XVIII ${ }^{20}$. En este sentido, es muy difícil sostener la lectura de R. Hočevar (quien interpreta a Hegel como un reformista del Código Civil ${ }^{21}$, puesto que ésta implica producir un forzamiento interpretativo de los textos que sólo puede realizarse negando el pensamiento político hegeliano, y mutatis mutandis, la filosofía hegeliana misma. El ejemplo del Código sancionado en Prusia le proporciona a Hegel la oportunidad de contar con un claro antecedente a criticar en el caso de los debates de Württemberg, puesto que, al interceder en esta cuestión, no solamente interviene en un problema local sino que reflexiona acerca de elementos fundamentales de su teoría política. En este sentido, nuestro trabajo no busca determinar si Hegel tenía o no razón en sus consideraciones, sino, más bien, aspira a exponer la reformulación del concepto de "privilegio".

\section{III}

Un posible objetor de nuestros estudios podría señalar: ¿Por qué los derechos especiales de cada uno de los estamentos no podrían ser interpretados como las

19 Hegel se refiere una vez al Allgemeines Landrecht y a Johann Heinrich Casimir Graf von Carmer, uno de sus redactores. No obstante, la cita en cuestión tiene lugar en el contexto de la discusión sobre el status de la pena, y no sobre cuestiones vinculadas con la organización del Código. Cfr. G. W. F. Hegel, "Fragmente historischer und politischer Studien aus der Berner und Frankfurter Zeit", en Werke in zwanzig Bänden, editadas por Eva Moldenhauer y Karl M. Michel, Frankfurt am Main, Suhrkamp, 1996, t. I, Fragmento 16, p. 443.

20 La conocidas citas se encuentran en la versión publicada de la Filosofia del Derecho, G. W. F. Hegel, "Grundlinien der Philosophie des Rechts", en Werke..., op. cit., t. VII, § 99 y § 101. Para la traducción al español, véase G. W. F. Hegel, Principios de la Filosofia del Derecho, tr. J. L. Vermal, Buenos Aires, Sudamericana, 1975 (y reediciones). Dado que la traducción española respeta la numeración de los parágrafos del texto original, se omiten las referencias a la traducción en los casos en los que se cita el parágrafo del texto alemán.

21 El problema del trabajo de Hočevar es que él rescata los elementos en común ( $v$. g. la organización de la sociedad civil en torno a estamentos) omitiendo las profundas diferencias en torno a la mediación entre estamentos y el Estado, o a la articulación entre los poderes que existen entre la Filosofía del Derecho de 1821 y Allgemeines Landrecht. Cfr. R. Hočevar, "Hegel und das Allgemeine Landrecht für die Preussischen Staaten von 1794“", en Der Staat, 1972, 11, pp. 189-208; idem, Hegel und der Preußische Staat, München, Wilhelm Goldmann, 1973, pp. 13-53. Nos distanciamos de la interpretación de Hočevar, pero también de la lectura de O. Pöggeler, quien sugiere que Hegel habría discutido la cuestión de los privilegios estamentales pensando en una reforma del modelo austríaco (conceptualmente prerrevolucionario), y el comentario de H.-C. Lucas, quien considera la crítica hegeliana a los privilegios estamentales sin reparar en la resemantización de dicho término que el filósofo de Stuttgart lleva a cabo. Cfr. O. Pöggeler, "Hegels Option für Österreich. Die Konzeption korporativer Repräsentation", en Hegel Studien, 12, 1977, pp. 83-128; H.-C. Lucas, "Wer hat die Verfassung zu machen, das Volk oder wer anders?”, en H.-C. Lucas y O. Pöggeler (eds.), Hegels Rechtsphilosophie im Zusammenhang mit der europäischen Verfassungsgeschichte, Stuttgart / Bad Cannstatt, Fromann-Holzboog, 1986, pp. 175-220, aquí p. 205 y ss. 
mediaciones entre individuo y Estado que Hegel busca sostener? ¿Acaso no podrían ocupar los privilegios ese vacío -potencialmente revolucionario- que Hegel aspira a superar? La respuesta a este interrogante debe ser entendida en dos direcciones. Por una parte, es preciso referirse al sentido y alcance con que Hegel rechaza las prerrogativas estamentales, y por otra, es menester exponer la redefinición que Hegel propone de este concepto para poder integrar los estamentos al Estado como verdaderas mediaciones entre el individuo y las instituciones.

Por el contrario, Hegel sostiene tres tesis en contra de los privilegios (i.e. los defendidos por los estamentos en contra del monarca), a saber:

1. Los privilegios estamentales son antiestatales.

2. Los privilegios estamentales no son compatibles con la idea de una estatalidad orgánica, la base ética de los ciudadanos, su "convicción" (Gesinnung) y con la idea de un "sentido del Estado" (Sinn des Staates).

3. Las leges speciales obstaculizan la unidad del Estado, poniendo el orden político al borde de la revolución.

En el contexto de la discusión sobre la sanción de la Constitución de Württemberg, en los años 1815-1816, Hegel polemiza con los representantes de los distintos estamentos defendiendo la posición del rey, puesto que entiende que esta última es la que, verdaderamente, opone la visión de una estatalidad moderna frente a una concepción tardofeudal, signada fundamentalmente por la yuxtaposición de privilegios estamentales que limitan el poder del rey y que, asimismo, no son controlados por nadie, constituyendo así, según la definición de Hegel, "un principado no soberano". Es de particular relevancia detenerse en este debate, pues Hegel ofrece argumentos precisos contra las objeciones de la Asamblea de los estamentos frente al proyecto de constitución presentado por el rey Federico, y en paralelo, anticipa núcleos conceptuales que serán desarrollados en su Filosofía del Derecho de 1821. El problema de los privilegios estamentales, los cuales, de modo ordinario, son defendidos con el argumento de que contribuyen al bien común, es que, ante todo, obstaculizan la unidad del Estado. Cuando ciertos estamentos poseen la potestad de administrar impuestos que no son regulados por el Estado se ponen por fuera de las instituciones políticas, dado que no son controlados por nadie ${ }^{22}$. El reclamo de los estamentos por conservar los derechos a decidir sobre una parte de la administración del Estado pone ex hypothesi a estos actores por fuera del Estado, puesto que éstos obedecerán a una instancia que no tiene que ver con el orden público. Consecuentemente, Hegel tematiza la cuestión impositiva, tópico respecto del cual se encuentran anexos otras prerrogativas vinculadas al nombramiento, a la contratación de funcionarios, y a la

22 Hegel sostiene: "El pasaje de la gestión de una propiedad privada a la administración de los derechos del Estado es uno de los cambios más importantes que se han introducido en nuestros tiempos, y no ha dejado la situación de los funcionarios en las mismas condiciones que reinaban en la antigua constitución würtemburguesa; se trata de una de las transformaciones que han consolidado y permitido a Würtemberg el pasaje general de su posición de un principado no soberano a un Estado [nicht souveränen Fürstentum in einen Staat]", G. W. F. Hegel, " $\{$ Beurteilung der\} Verhandlungen in der Versammlung der Landstände des Königsreichs Württemberg im Jahr 1815 und 1816“, en: Werke..., op. cit., t. IV, pp.462-597, aquí p. 479. Para la traducción al español, véase G. W. F. Hegel, "Examen crítico de las Actas de la Asamblea de Estamentos del reino de Würtemberg en los años 1815 y 1816", en Dos escritos políticos, tr. K. Sauerteig, México, Universidad Autónoma de Puebla, 1987, pp. 22-23. Las llaves son indicaciones del editor. Al referirnos a este texto, indicamos la página de la traducción española y luego la referencia del texto original. 
redefinición de alícuotas y retribuciones correspondientes a los impuestos devenga$\operatorname{dos}^{23}$. Desde la perspectiva hegeliana, el carácter antiestatal del sistema impositivo reclamado por la Asamblea es doble: por una parte, invocando el antiguo derecho, la Asamblea pretende sostener un sistema tributario en el cual no puede intervenir el monarca, y tampoco puede llevar a cabo controles retrospectivos. En este sentido, ésta opera como un órgano cuya dependencia del Estado no es del todo precisa, en la medida en la cual la autoridad máxima del orden público queda privada siquiera de la posibilidad de decidir sobre dicho régimen ${ }^{24}$. Según Hegel, esta visión no obedece a la defensa de un derecho fundado en la capacidad técnica de los estamentos, ni en su presunta honradez (i.e. ética pública), ni mucho menos, en la defensa de un orden político orgánicamente articulado. Por el contrario, el presupuesto que opera por detrás de esta discusión no es sino una provecta concepción del orden estatal. Así, él escribe: “...el servicio a la persona del príncipe y los gastos de la corte son una cosa bien distinta de los servicios prestados al gobierno y al Estado"25. Si la Asamblea sostuviera al menos en parte la primera consideración, sería a todas luces evidente no sólo la imposibilidad de llegar a un acuerdo acerca de la sanción de una Constitución, sino también la insuperable dificultad de componer un Estado soberano, puesto que la Asamblea se estaría arrogando la representación de los intereses del pueblo frente a un poder principesco que se ubicaría simétricamente en contra de ellos. Desde el momento en el cual una asamblea de estamentos se enfrenta simétricamente al poder del príncipe a los efectos de defender los intereses del pueblo, presumiendo que el poder soberano promueve los intereses (privados) de la Corte contra el pueblo, la unidad del orden político es insalvable.

Una interpretación más crítica de la posición de la Asamblea también es posible: en el caso de Württemberg (hasta 1806), el ejercicio de la Asamblea se encontraba bajo las garantías del Imperio, lo cual implicaba limitaciones concretas en la toma de decisiones, puesto que sus resoluciones estaban supeditadas prima facie a las del Imperio. En principio, si éste decidía imponer un impuesto extraordinario a causa de un acontecimiento de igual carácter, la Asamblea de un principado no podía rechazar esta medida so pretexto de poner en cuestión la pertinencia o legitimidad de dicho gravamen. Por el contrario, una vez caído el Imperio, las disposiciones de la Asamblea pasan a formar parte de las resoluciones mismas de un orden estatal (o al menos, de un orden que aspira a esta condición) cuyas decisiones son constitutivas del mismo. Estas decisiones no son meramente técnicas ni strictu sensu administrativas, sino que constituyen las disposiciones cuyo resultado es el devenir mismo del Estado, frente a las cuales no es posible sostener una "neutralidad pasiva" (passive Neutralität). Hegel sostiene:

23 Hegel afirma: "Este privilegio [el derecho de la antigua asamblea a administrar directamente la caja de impuestos] implicaba que no solamente podía otorgarse a sí misma indemnizaciones, sino también nombrar funcionarios, consultores y, sobre todo, un comité, asignando retribuciones provenientes de dicha caja a éste y a aquellos empleados. Así, el mismo comité administraba la caja de la que obtenía retribuciones que en conjunto le eran fijadas por la asamblea; este derecho de gestión llegaba tan lejos que el comité decretaba suplementos de pago y gratificaciones, aprobaba y pagaba compensaciones y pensiones a sus propios miembros y a otras personas por servicios imaginarios. Esta disponibilidad del ingreso público para fines personales, que el honor impide en general mantener en secreto, estaba en los hechos, fuera de todo control", Ibidem, pp. 38, 500-501.

24 Hegel se refiere particularmente a un escándalo suscitado hacia 1796, en ocasión de la presentación de los balances correspondientes al período 1771-1796, los cuales no habrían coincidido con la documentación presentada oportunamente.

25 G. W. F. Hegel, “\{Beurteilungen der\} Verhandlungen...”, op. cit., pp. 21, 477. 
El Estado tiene ahora necesidad de todas aquellas nuevas garantías contra el espíritu particularista y las usurpaciones de la asamblea, porque ya no existen las garantías que obtenía del emperador y del imperio; con ello ha aparecido un elemento totalmente nuevo, lo político [das Politische], elemento que la dieta prefería anteriormente ignorar y en el cual se halla ahora inmersa ${ }^{26}$.

Hegel interpreta como inadmisible la responsabilidad institucional que, desde el punto de vista de la soberanía, implican las decisiones que se tomen en el marco de un Estado, puesto que, caído el Imperio, no es posible sustraerse a la discusión acerca del reordenamiento político -en este caso- de Württemberg, en la cual no puede defenderse la neutralidad de una Asamblea.

Uno de los ejemplos clave que Hegel plantea en este sentido es el caso de los escribanos, quienes puntualmente en Württemberg tenían el privilegio de poder retrasar o acelerar diferentes cuestiones administrativas según su arbitrio ${ }^{27}$. Los alcaldes y administradores no tenían el derecho a redactar sus cuentas de gestión porque esto era un derecho conquistado por los escribanos. Así, nos encontramos nuevamente con una instancia fundamental para el curso ordinario de las instituciones políticas que utiliza un determinado requisito para obturar el funcionamiento del Estado a condición que se vean satisfechas sus demandas.

La segunda tesis apunta a dar cuenta de la constitución orgánica del Estado, no tanto a las instituciones políticas consideradas en modo aislado. Según Hegel, el organicismo del Estado está dado, ante todo, por la interacción funcional de las diferentes instancias de las instituciones (aunque también del orden político en general), cada una de las cuales constituye un momento de lo estatal entendido como una totalidad ética (familia, sociedad civil y Estado). Al rechazar un comentario crítico a la cuestión de las condiciones para ser elegido y para ser elector en la Asamblea (tema sobre el cual se concentrará en el Reform Bill de 1831), Hegel denuesta la posición que defiende que los criterios para sufragar o ser representante deban depender exclusivamente de la edad de veinticinco años y de la posesión de una renta mínima anual, puesto que este condicionamiento no presenta nexo alguno ni con el Estado, en un sentido amplio del término, ni con el conjunto de las instituciones de la sociedad civil. Por el contrario, la estipulación de criterios que no presupongan una ética estatal no sólo incurre en la arbitrariedad de ofrecer una mala mediación ${ }^{28}$, sino que prediseña un fundamento ético para la futura Asamblea que se sostendrá en el universo de valores que esté asociado a una determinada edad y a una renta específica. Como señala Hegel:

...los electores no tienen ninguna relación ni con el orden civil, ni con una organización de la totalidad del Estado [Staatsganzen]. Los ciudadanos aparecen como átomos aislados [isolierte Atome], las asambleas electorales como agregados des-

\footnotetext{
Ibidem, pp. 29, 488 .

Ibidem, pp. 93, 572

28 La idea hegeliana de "mala mediación" puede ser interpretada de distintas maneras, pero fundamentalmente remite siempre a una errónea articulación entre lo universal y lo particular. En lo relevante para este contexto, Hegel rechaza los criterios para acceder a la Asamblea que carecen de un nexo ético con el conjunto de convicciones que debe poseer todo funcionario público. Sobre el límite de aquello que debe ser regulado en lo concerniente al rechazo del laissez faire, véase K. Vieweg, Das Denken der Freiheit. Hegels Grundlinien der Philosophie des Rechts, München, Fink, 2012, p. 309 y ss.
} 
ordenados e inorgánicos y el pueblo en general se disuelve en una multitud [Haufen] - forma bajo la cual una comunidad [Gemeinwesen] jamás debe presentarse cuando acomete una acción; se trata de su figura más indigna y la que más contradice su concepto que es el de ser un orden espiritual [geistige Ordnung]. La edad e incluso la renta son cualidades que sólo conciernen al individuo en cuanto tal, y no propiedades que constituyen su valor en el orden cívico [...] La imaginación popular tiene en tal estima esa clase de valor que sólo se dice de un hombre que es alguien si ha obtenido un empleo, un rango de maestro y su ha sido admitido en una esfera civil determinada; por el contrario, de alguien que tiene 25 años y una renta inmobiliaria de 200 florines anuales o más, se dice que es nada. Si una constitución hace de él algo, un elector, ella le concede un alto derecho político sin que tenga relación alguna con los otros elementos de su existencia civil... ${ }^{29}$.

Como veremos, la posición de Hegel es diametralmente opuesta, puesto que sostiene que la auténtica estatalidad sólo puede estar orgánicamente mediada a través de articulaciones que favorezcan la vitalidad de cada uno de los miembros del Estado. La condición a evitar es aquélla en la cual se produce una mala mediación entre individuo y Estado, como se da -según Hegel- en las teorías del iusnaturalismo moderno, o entre formaciones inorgánicas de individuos, que aparecen frente al Estado como un agregado de átomos, sin vínculo sustancial alguno que los sostenga. Esto atenta contra la constitución de una ética estatal: un fundamento subjetivo que incline espontáneamente a obedecer las leyes que no dependa de las circunstancias eventuales que se presentan en la cotidianeidad. De igual modo, sería erróneo presuponer que no fuera razonable augurar un conjunto de acciones a partir de los criterios propuestos por la Asamblea: no se trata aqui de contraponer un ideario ético al azar, sino por el contrario, lo que se busca es señalar cuáles son las consecuencias que se siguen de introducir en las instituciones criterios extraños que, por una parte, no tienden hacia la finalidad que se persigue, y que por otra, introyectan condiciones que propenden hacia la defensa de los intereses privados o las arbitrariedades. De aquí que Hegel subraye la fuerte oposición entre la integración y el reconocimiento que posee un sujeto dentro de una rama específica del trabajo y de la vida civil en general. De modo concomitante, se expone la idea de una ética estatal bajo la forma de un sentido del Estado (Sinn des Staates) $)^{30}$, un fundamento que se sitúa en el orden de la convicción interna que inclina a los

${ }_{29}$ G. W. F. Hegel, “\{Beurteilungen der\} Verhandlungen...”, op. cit., pp. 24-25, 479-480. Una parificación con el citado ejemplo puede hallarse en la justipreciación hegeliana del derecho romano, tal como aparece en los Grundlinien..., en donde impugna las tesis de Gustav Hugo acerca de la presunta racionalidad del derecho romano. En efecto, Hegel no sólo evalúa críticamente distintas instituciones de la Antigua Roma (v. g. la ley que concedía al acreedor el derecho de matar o vender como esclavo al deudor una vez vencido el plazo del cumplimiento de la obligación asumida), sino que incluso llega a celebrar la falta de cumplimiento en virtud de los fundamentos arbitrarios sobre las que estarían sostenidas. Tal como es señalado: "Cuando la justificación histórica confunde la génesis a partir del concepto con la génesis exterior, realiza inconscientemente lo contrario de lo que se propone”, G. W. F. Hegel, "Grundlinien...", op. cit., VII, § 3.

30 Hegel explica: "El significado de este término no se limita a la posesión de una inteligencia penetrante ni a la simple honradez o a la buena intención hacia el bienestar común y hacia los particulares [...] el sentido del Estado [Sinn des Staates] se adquiere sobre todo ocupándose directamente de los asuntos de interés universal, en los cuales no solamente se siente y se reconoce el valor infinito que lo universal tiene en sí mismo, sino que se hace en profundidad la experiencia de la resistencia, la hostilidad y la deshonestidad del interés privado y de la lucha que ello implica, particularmente contra la tenaz obstinación que se atrinchera en las formas jurídicas", G. W. F. Hegel, “\{Beurteilungen der\} Verhandlungen...”, op. cit., pp. 19-20, 475. 
ciudadanos a obedecer las leyes y a actuar en vistas del "interés universal" no en virtud del azar, sino a causa de la espontaneidad que encuentra su hontanar en la convicción interna (Gesinnung) que ellos poseen. Las instituciones políticas funcionan de acuerdo a lo esperado no por razones insondables o arbitrarias sino porque las mediaciones se encuentran articuladas a través de aquellas instancias que favorecen la organicidad del Estado. Es probable que algunos individuos obedezcan las leyes por razones lucrativas, por deber o por miedo al castigo, pero no es sino este sentido del Estado el que, en rigor, sostiene la conformación de un sustrato ético sólido sobre el cual se apoyan las instituciones, respecto de las cuales el interés privado queda claramente confinado. Asimismo, Hegel se concentra en exponer con claridad la necesaria subordinación de la Asamblea al Estado, no meramente a la Corte o al príncipe. Un Estado orgánico no puede permitir la pervivencia de momentos interiores al parlamento que existan con una relación imprecisa o azarosa respecto de las instancias concomitantes.

Por último, Hegel se refiere en no pocos pasajes a la peligrosidad que implica la situación en la cual se incurre cuando se sostienen los privilegios estamentales de la manera en la cual han sido presentados, en una patente incompatibilidad con el orden estatal y bajo una muy compleja posibilidad de articularlos con una concepción orgánica del Estado. Así, el autor de la Ciencia de la Lógica interpreta que el sostenimiento de una oquedad entre la Asamblea y el poder monárquico, por una parte, y el pueblo, por otra, no puede conducir sino a una revolución, algo que Hegel se esfuerza por evitar, dado que, entre otras razones, nunca es posible dimensionar las (irracionales) consecuencias posibles de un fenómeno semejante. Si bien es cierto que el joven Hegel hubo de celebrar el ideario revolucionario hacia 1789, rápidamente se vuelve crítico del mismo al notar, en lo doctrinal, el carácter abstracto de las doctrinas defendidas; mientras que en lo referido a los sucesos políticos percibe el elemento autodestructivo y anárquico de la Revolución, el cual no puede ser dominado por los protagonistas de la misma. En este sentido, el binomio reforma-revolución se patentiza aquí de manera elocuente, puesto que, en el contexto alemán, describe una alternativa inflexible, correlativa a la dualidad orden-caos, respecto de la cual, cuando menos en el horizonte de percepción en el cual escribe Hegel, es conflictivo (o imposible) pensar en una alternativa superadora al mismo. De esta manera, al referirse al derecho electoral inglés ${ }^{31}$, Hegel asevera que, en el caso en el cual las reformas invocadas no tuvieran lugar, de aquí se seguiría una imposibilidad de que el pueblo pudiera encontrar -tanto en la monarquía como en la Asamblea- un modo de expresar esta problemática. En este sentido, la alternativa para éste sería clara:

Si, no obstante, el proyecto debiera, más aún por su principio que por sus disposiciones, abrir a los principios enfrentados al sistema hasta ahora vigente el camino al Parlamento, y con ello al centro del poder gubernativo, de modo que, con más significado del que pudieron recabar los reformadores radicales habidos hasta la

31 Hegel escribe el Reform Bill en ocasión del debate parlamentario sobre la reforma del derecho electoral. Básicamente, el proyecto de reforma inglés proponía una nueva proporción de representantes en el Parlamento, de acuerdo con la cantidad de habitantes. Por ejemplo, las ciudades con menos de 2000 habitantes (unas 60) perdían el derecho a representación, las que tenían entre 2000 y 4000 (47 en total) pasaban de dos bancas a una; muchas ciudades hasta entonces sin representación pasaban a tenerla; a varias grandes ciudades se les concedían 2 bancas en lugar de una (v. g. Manchester, Leeds y Birmingham, entre otras), etc. 
fecha, pudieran allí mismo entrar en escena, la lucha amenazaría con hacerse tanto más peligrosa por cuanto entre los intereses de los privilegios positivos y las exigencias de la libertad más real no habría ningún poder superior mediador para contenerlos y confrontarlos, a causa de que aquí el elemento monárquico carece del poder por el que otros Estados pudieron agradecerle el tránsito de la legislación anterior fundada sólo en derechos positivos a una basada en los principios de la libertad real; tránsito, por cierto, mantenido libre de conmoción, violencia y robo. El otro poder sería el pueblo; y una oposición construida sobre un fundamento ajeno hasta ahora a la composición del Parlamento, que no se sintiera en el Parlamento a la altura del partido enfrentado, podría ser seducida a buscar en el pueblo sus fuerzas y, entonces, a suscitar, en vez de una reforma, una revolución ${ }^{32}$.

En consecuencia, el sostenimiento de los privilegios estamentales no solamente implica un problema relativo a la representación política ni tampoco una cuestión vinculada con un ordenamiento más o menos eficaz de los distintos momentos del Estado. No se trata aquí de modernizar un aspecto procesual de las instituciones políticas, sino de poner en cuestión un elemento vital del orden político moderno, que strictu sensu ya no admite lugar en Estado ${ }^{33}$. Así, no es sino esta distorsión la que habría de conducir a la ruptura del orden político. Es por esta razón que, en el contexto del debate württemburgués, Hegel defiende la posición del príncipe Federico frente a los estamentos, dada la presencia de un quiasmo en comparación con la Revolución Francesa: si en 1789 el poder político defendía los privilegios y las leges speciales, en Württemberg es el príncipe quien los ataca, defendiendo un derecho público por encima de la controversia entre el alcance del poder de la Corte y las prerrogativas de los estamentos.

32 G. W. F. Hegel, "Über die englische Reformbill", en idem, Werke..., t. XI, pp. 83-128, aquí p. 129. Para la versión en español, véase G. W. F. Hegel, Sobre el proyecto de reforma inglés, tr. E. Maraguat, Madrid, Marcial Pons, 2001, p. 95. Referido a este tópico, en el texto sobre el debate de Württemberg Hegel se refiere a la posición de la Asamblea como aquella que "contiene ya el veneno de su principio revolucionario [Gift seines revolutionäres Prinzip]”, G. W. F. Hegel, “\{Beurteilungen der\} Verhandlungen...”, op. cit., pp. 59, 529. Como señala Villacañas Berlanga, el texto sobre el Reformbill no se refiere solamente a Inglaterra, sino que, de manera oblicua, reflexiona al mismo tiempo las consecuencias negativas de la "fortaleza desmedida del Parlamento", J. Villacañas Berlanga, L., La filosofía del Idealismo Alemán, t. II [La hegemonía del pensamiento de Hegel], Madrid, Síntesis, 1999, p. 223. Asimismo, es menester agregar aquí que la posición de Hegel rechaza la postura antirrevolucionaria del historicismo de la Escuela Histórica del Derecho (ante todo, Savigny). En efecto, como señala Bobbio, frente a Hegel, la Escuela Histórica opone el peso de la costumbre y la historia frente a la voluntad racional de la ley. Véase N. Bobbio, "Hegel y el iusnaturalismo“, tr. A. Rossi, en G. Amengual Coll (ed.), Estudios sobre la «Filosofia del Derecho» de Hegel, Madrid, Centro de Estudios Constitucionales, 1989, pp. 377-406, aquí p. 381.

33 Al referirse a los privilegios en las monarquías feudales, Hegel indica: "Montesquieu reconoce al honor como principio de la monarquía porque no considera ni la monarquía patriarcal o antigua, ni la que ha evolucionado hasta la constitución objetiva [objektiver Verfassung], sino la monarquía feudal, y más precisamente, en cuanto las relaciones de su derecho político interno se han asegurado [befestigt ] en propiedades privadas jurídicas y en privilegios de individuos y corporaciones. En tanto en esta constitución la vida del Estado se basa en una personalidad privilegiada, en cuyo arbitrio [Belieben] está depositada una gran parte de aquello que debe hacerse para el sostenimiento del Estado, lo objetivo de estas acciones no se encuentra establecido como deber, sino en la forma de pareceres y opiniones, lo que hace que lo que mantenga unido al Estado sea el honor en vez del deber", G. W. F. Hegel, "Grundlinien...", op. cit., § 273, Obs. Véase también idem, "Enzyklopädie der philosophischen Wissenschaften“, en Werke..., op. cit., t. X, § 544. Sobre el atraso provocado por los privilegios estamentales, R. Koselleck, Preußen zwischen Reform und Revolution, op. cit., cap. 4. 
Por tanto, la mezquina defensa de las prerrogativas estamentales no implica meramente el sostenimiento de un monstrum jurídico incompatible con la estatalidad moderna, sino que pone además en peligro la constitución total del orden de lo real, en la medida en que, en el contexto de los sucesos revolucionarios en el vecino país, se incremente la posibilidad de que sean receptadas las ideas rupturistas contrarias a la vía de la reforma política.

\section{IV}

Ahora bien, un lector de este trabajo que haya seguido nuestro razonamiento hasta aquí, no sin razón podría interrogarse: ¿acaso no es Hegel el pensador que aspira a superar el atomismo moderno y el hiato entre individuo e instituciones a través de los estamentos, los cuales, al presentar mediaciones ligadas a los diferentes oficios y profesiones, logran integrar a los individuos en subesferas que luego serán armonizadas por el Estado, entendido como totalidad ética? Si los privilegios estamentales se ocupan de precisar las funciones de cada estamento al interior del Estado, ¿no podrían ser interpretados, precisamente, como las mediaciones teorizadas para superar el vacio entre los ciudadanos y el monarca? ¿Cuál sería el argumento específicamente hegeliano para revisar estas tradiciones de fuerte arraigo en los estados alemanes? Entendemos que la respuesta a estas atendibles objeciones tiene que buscarse en la redefinición que Hegel ofrece del término "privilegio", así como en la integración de los estamentos por arriba y por abajo que propone en su teoría ${ }^{34}$.

En la versión más sistemática de su teoría del $\operatorname{Estado}^{35}$, Hegel propone una monarquía constitucional con una división en tres poderes (poder del príncipe, poder legislativo y poder gubernativo), cuyo poder legislativo se articula en torno a una asamblea bicameral de estamentos. Los diputados no representan a los individuos de manera atomística sino a través de las esferas de la sociedad civil: estamentos y corporaciones, lo cual remite a la tipificación hegeliana de la división estamental de las ramas del trabajo, las cuales habrán de tener una representación política en dicho parlamento, conforme a su naturaleza y función en el Estado. En este sentido, Hegel rechaza la representación política según la cual el diputado tiene vínculo espiritual con la nación sin que exista mediación alguna con ésta ${ }^{36}$. Por el contrario, luego de escindir de manera discreta el ámbito de la sociedad civil del Estado en sentido estricto, Hegel presenta como mediaciones entre estos dos ámbitos a los estamentos ${ }^{37}$

34 Sin aspirar a desarrollar este punto, es relevante indicar que la discusión en torno a la definición del término "privilegio" y la disposición de legalidades especiales para diferentes segmentos de sociedad civil mutatis mutandis puede encontrar una patente actualidad en debates contemporáneos acerca de la idea de justicia y el concepto de mérito en J. Rawls, Teoría de la justicia, tr. M. Dolores González, México, Fondo de Cultura Económica, 1979, cap. 3, y sobre las bases de una eticidad hegeliana para la democracia actual en el ensayo de reciente publicación de A. Honneth, El derecho de la libertad, tr. G. Calderón, Buenos Aires, Katz, 2014, cap. 2.

35 G. W. F. Hegel, "Grundlinien...", op. cit.

36 En sentido estricto, como veremos, Hegel no acepta el concepto de representación de Sieyès, conforme al cual la existencia de cuerpos intermedios entre representados y representante contribuiría a destruir la unidad mentada por este vínculo. Cita Sieyès: "Es necesario que los miembros de la sociedad ejerzan individualmente el poder constituyente", en Preliminaire de la Constitution. Reconnoissance et exposition raisonnée des Droits de l'Homme et du citoyen. Lu les 21 et 22 Julliet 1789, au Comité du Constitution, Paris, Assemblée Nationale, 1789, p. 20.

37 Hegel utiliza el término "estamento [Stand]" a los efectos de abarcar tanto un matiz económico como político, con un carácter técnico que él mismo precisa: "A pesar de que en las representaciones de las así llamadas teorías 
y las corporaciones. Mientras que aquéllos presentan una organización de la vida del trabajo al interior del sistema de necesidades, éstas ofrecen un modo de articular los elementos inorgánicos de la sociedad civil con el Estado.

Los estamentos se desprenden de los sistemas particulares de necesidades ${ }^{38}$. Hegel distingue entre: (a) el estamento sustancial o inmediato, (b) el estamento formal o reflexivo, y (c) estamento universal. Cada uno de éstos se vincula, respectivamente, con el trabajo de la tierra, con la industria (estamento que, a su vez, Hegel subdivide en artesanal, fabril y comercial) y con el "servicio del gobierno [Dienst der Regierung]". En medio de la contingencia de la sociedad civil, el individuo encuentra en su estamento la particularidad determinada (bestimmte Besonderheit), puesto que éste se realiza al interior de una esfera específica del sistema de necesidades. Asimismo, en ésta halla una particular disposición ética interna, la cual se compone de la integridad (Rechtschaffenheit) y el honor (Standesehre) de pertenecer a un estamento determinado. Así, el individuo se convierte en miembro de una rama específica del mundo laboral, en la cual habrá de encontrar su reconocimiento tanto en sí mismo como en los demás miembros. De esta manera, ya en la sociedad civil, al interior del sistema de necesidades, se presenta una organización de la misma que luego será entendida como fundamento para la articulación de las corporaciones, asociaciones que tienen "...el derecho a cuidar sus propios intereses, aceptar miembros según la cualidad objetiva de su destreza e integridad en un número que se determine por la situación general, y proporcionar cuidados a sus miembros ante circunstancias especiales como también para la educación respecto de la capacidad adscripta. Toma para ellos el lugar de una segunda familia". ${ }^{39}$ La corporación, por su parte, hallará su verdad (su realización) en la representación parlamentaria del Estado, puesto que la organización de estos intereses -legítimamente contrapuestos- debe ser armonizada a través de éste. ${ }^{40}$ De lo contrario, nos encontraríamos, por una parte, ante una yuxtaposición de intereses enfrentados entre sí, y por otra, ante un potencial conflicto entre los distintos límites de las diferentes esferas de la sociedad civil, contenidas tanto en los estamentos como en las corporaciones. ${ }^{41}$ Asimismo, éstas permiten que, aún en

[las que adoptan una perspectiva atomística] se han separado completamente los estamentos [Stände] de la sociedad civil de los estamentos [Stände] en sentido político, la lengua alemana ha conservado en la palabra Stand una reunión que, por otra parte, existía anteriormente”, G. W. F. Hegel, “Grundlinien...”, en Werke..., op. cit., § 303, Obs. Es interesante observar aquí que Hegel se hace eco de una discusión contemporánea a la sanción del Allgemeines Landrecht entre el citado penalista E. Klein y el jurista J. G. Schlosser en torno al status del término Stand como cuerpo intermedio entre los individuos y el Estado. Sobre este debate y el uso de los términos "Stand" y "Klasse" en el contexto en el cual Hegel escribe, véase el artículo "Stand, Klasse", en O. Brunner, W. Conze y R. Koselleck (eds.), Geschichtliche Grundbegriffe: Historisches Lexikon zur politisch-sozialen Sprache in Deutschland, Stuttgart, Klett-Cotta, 1990, vol. 6, pp. 233-247.

38 Según Hegel: "El conjunto total adopta la forma de sistemas particulares de necesidades, de sus medios y del trabajo, de modos de satisfacción y de cultura teórica y práctica, en los que se distribuyen [zuteilen] los individuos dando lugar a la diferencia de estamentos”, G. W. F., Hegel, “Grundlinien...”, op. cit., § 201.

39 Ibidem, $\S 252$.

40 Ibidem, $\S \S 304-311$.

41 Al interior del Estado, los estamentos tendrán una representación política en el parlamento. Como señala $\mathrm{H}$. Schnädelbach, “...los estamentos representan lo social en lugar de lo político, pero no en la forma de meros electores yuxtapuestos, sino en la forma articulada socialmente. Sólo así existen los individuos para el Estado, y no en la forma de ciudadanos entendidos como personas privadas aisladas o en su particularidad abstracta-universal”, H. Schnädelbach, "Die Verfassung der Freiheit”, en L. Siep (ed.), Grundlinien der Philosophie des Rechts, Berlin, Akadamie Verlag, 1997, pp. 243-265, aquí p. 257. Sobre la representación política de los estamentos, véase G. W. F. Hegel, “Grundlinien...”, op. cit., § 301 y ss. Sobre este tema, G. Duso, "La libertà politica nella Rechtsphilosophie hegeliana: una traccia”, en G. Duso y G. Rametta, La libertà nella filosofia classica tedesca. 
el plano de la contingencia de la sociedad civil, los individuos puedan sentirse contenidos por un sistema de dependencias que no solamente habrá de asistirlos y defenderlos en casos de necesidad, sino que les proporcionará una "convicción interna [Gesinnung]", la cual habrá de operar como sustrato ético para el libre desarrollo de su respectiva actividad laboral y, de manera concomitante, en su articulación con el Estado. Así, estamentos y corporaciones no sólo constituyen momentos utilitarios de la sociedad civil, instituciones a las cuales los individuos recurren en caso de necesidad o en aquellas situaciones en las cuales se ven enfrentados a solucionar conflictos producto de las arbitrariedades contenidas en el sistema de necesidades. Por el contrario, Hegel destaca el elemento ético e identitario que define a estas instituciones por sus miembros, y viceversa, a sus miembros por estas mismas instituciones. De esta manera, por medio de los estamentos, Hegel no busca legitimar una aristocracia por encima del conjunto de la sociedad a través de un sistema de derechos especiales, sino que se aspira a determinar con claridad cuáles son las mediaciones existentes entre la sociedad civil y el Estado, las cuales presentan su concreción determinada en estamentos y corporaciones. Al interior de los momentos inorgánicos de la sociedad civil, dentro de la cual tienen lugar las diferentes actividades que los individuos, guiados por su arbitrio, llevan a cabo, Hegel determina al trabajo como el gozne que será el fundamento para la mediación entre estos dos ámbitos, puesto que la división en diferentes esferas del sistema de necesidades se articula en torno a él.

En consecuencia, Hegel recusa absolutamente la idea de privilegios nobiliarios que el orden estatal debería admitir bajo la aceptación del argumento del bien común. ${ }^{42}$ En lo que podría interpretarse como una clara referencia al debate sobre los privilegios estamentales, Hegel sostiene:

Los privilegios [Privilegien], comprendidos como derechos de una rama de la sociedad civil agrupada [gefaßten] en una corporación, se diferencian de los privilegios entendidos propiamente según su etimología, por el hecho de que estos últimos son excepciones de la ley general entendida según una accidentalidad, mientras que los primeros son determinaciones legales que se encuentran en la naturaleza de la particularidad de una rama esencial de la sociedad ${ }^{43}$.

Esta diferencia entre los dos matices del término privilegio es fundamental para comprender un tópico que yace en el centro de las discusiones en torno al debate so-

Politica e filosofia tra Kant, Fichte, Schelling e Hegel, Milano, Franco Angeli, 2000, pp. 171-185, aquí pp. 183185.

42 Como ha estudiado A. Schwennicke, el argumento habitual para defender el régimen de leges speciales en torno a las discusiones en la elaboración del Allgemeines Landrecht era el del "fin último del Estado [Haupendzweck des Staates]" o el "bien común [gemein Wohl]" del orden político. Cfr. Allgemeines Landrecht, op. cit., Intr. § 57; II, 13, §§ 3-4. Cfr. A. Schwennicke, Die Entstehung der Einleitung..., op. cit., p. 237 y ss.

43 G. W. F. Hegel, "Grundlinien...“, op. cit., § 252, Obs. Esta diferenciación halla un paralelo en las Lecciones sobre Filosofía del Derecho. Así, en el curso de 1817-1818 Hegel enfatiza la importancia de la escisión de la sociedad civil en corporaciones entendidas como esferas con fines particulares, cuya articulación aparece con claridad en el sistema de las necesidades. Asimismo, en el curso del año 1819-1820 se destaca con relevancia los elementos éticos (i. e. el honor y el reconocimiento) propios de la pertenencia a una corporación específica. G. W. F. Hegel, Vorlesung über Naturrecht und Staatswissenschaft. Heidelberg 1817/18 mit Nachträgen aus der Vorlesung 1818/19. Nachgeschrieben von P. Wannenmann, editado por C. Becker, W. Bonsiepen et alii, Hamburg, Felix Meiner, 1983, § 121; "Vorlesungen über die Philosophie des Rechts" [editado por D. Felgenhauer], en Gesammelte Werke, t. XXVI, 1, Hamburg, Felix Meiner, 2013; p. 506 y ss. 
bre la Constitución de Württemberg y que se relaciona directamente con la hipotética contribución que Code civil de 1804 llevaría a cabo para eliminar los privilegios estamentales en Alemania. El privilegio entendido como la especialización organizada de una rama laboral de la sociedad civil, lejos de implicar un perjuicio para el orden estatal in toto, constituye una virtud para el mismo, puesto que, independientemente de las respectivas contingencias, permite que la articulación entre sus elementos inorgánicos se produzca armoniosamente en su relación con las corporaciones y con el Estado, instancia última encargada de neutralizar las divergencias que tengan lugar en dicha mediación. Por el contrario, el privilegio entendido como excepción a la ley (v. g. beneficios impositivos o prerrogativas para el comercio) constituye un residuo premoderno que, bajo el recurso del bien común y de la conducción paternalista de la sociedad, ha conspirado contra una organización política moderna en la cual se cristalice verdaderamente la igualdad ante la ley. Por el contrario, la estatalidad moderna no puede seguir sosteniendo los privilegios feudales al interior de su propio orden político, ante todo, por la hibridez que esto supone, ya que no sólo contribuye a incrementar las desigualdades al interior de la sociedad civil y del Estado, sino que neutraliza o envanece el funcionamiento de los diferentes momentos del todo político.

En suma, a través de la relectura del término "privilegio", en íntima relación con la exposición de los estamentos y de las corporaciones como nexos orgánicos entre el individuo y el Estado Hegel alcanza a superar el problema de la oposición entre el monarca y la asamblea de estamentos. Los privilegios no constituyen leyes privadas que se oponen a la legislación universal, sino que éstos son sus particularizaciones, que especifican una rama laboral de la sociedad y al mismo tiempo, a través de las corporaciones, hilvanan las instancias por medio de las cuales los elementos inorgánicos de la sociedad son reconducidos al Estado, concretamente, en el parlamento.

A lo largo de estas páginas hemos intentado exponer la crítica de Hegel a los privilegios estamentales y la redefinición del concepto de privilegio, noción a través de la cual el filósofo alemán logra pasar de una concepción en la cual los estamentos se encuentran enfrentados al monarca, a una situación en la cual éstos se hallan integrados al Estado. Como han señalado las investigaciones de Mohnhaupt o de Canale, los privilegios estamentales distaban de ser en Alemania una cuestión menor o de relevancia exclusiva para juristas. Por el contrario, la cuestión de los privilegios era de una importancia fundamental: la defensa de las prerrogativas estamentales (excepciones a la ley, derechos especiales, inmunidades, etc.) son para Hegel (1) claramente antiestatales, puesto que atentan contra la soberanía del Estado, en la medida en que éstas se oponen al poder del príncipe, confiriendo así al orden político el carácter de un "principado no soberano". Luego (2), Hegel rechaza este tipo de privilegios porque conspiran contra la organicidad del Estado ( $v . g$. las condiciones para elegir y ser elector dependen de criterios que no se relacionan ni con la eticidad, con un "sentido del Estado"). Por último (3), del hecho de que los privilegios estamentales sean entendidos como la defensa de intereses privados frente al bien público se sigue que las posibilidades de que la vía revolucionaria para transformar el orden político encuentre una mayor presencia en todos aquellos actores que no 
perciban en las instituciones políticas un médium para armonizar las tensiones y los conflictos inherentes en la sociedad civil, sino que vean en éstas un instrumento para prolongar un conjunto de relaciones específicas de poder. Hegel repara en la alta peligrosidad de que se conforme una ética "antiestatal" en aquellos sujetos que no perciben a las instituciones políticas instancias armonizadoras de las contradicciones propias de la sociedad civil. El Estado tiene que celar por evitar que estos fenómenos tengan lugar, ya que estos implican la conformación de una autoconciencia que se manifiesta no en contra de un monarca o de una asamblea en particular, sino en contra el Estado en sí mismo. Queda aquí evidenciado, pues, que el concepto hegeliano de "privilegio", comprendido como un despliegue orgánico de las diferentes ramas del trabajo no sólo es plenamente compatible con el orden estamental, sino que es la herramienta idónea para realizar el nexo entre los estamentos y las corporaciones, puesto que los criterios en virtud de los cuales dichos vínculos son producidos garantizan la presencia de un sentido del Estado en sus miembros. De este modo, la ética estatal queda cobijada bajo la organicidad del Estado hegeliano, condición que impide que los estamentos puedan siquiera formular la posición según la cual se encontrarían en condiciones de defender intereses privados frente al monarca.

En síntesis, la concepción de los privilegios estamentales presente en el trasfondo de discusión del Allgemeines Landrecht y defendida por la Asamblea de Estamentos en el debate sobre la Constitución de Württemberg no es armonizable con la estatalidad orgánica hegeliana, puesto que (a) sostiene la existencia de instituciones políticas por fuera de la regulación del Estado, (b) no repara en la fundamental relevancia de fortalecer un sentido del Estado en los ciudadanos que opere como núcleo subjetivo de la eticidad, garantía del buen funcionamiento de las instituciones, y (c) no percibe la peligrosidad de que dicho orden político pueda conducir a una revolución. Por el contrario, la comprensión hegeliana de los privilegios logra superar este conflicto a través de la redefinición de este concepto no ya dependiente de una tradición jurídica monárquica del siglo XVIII, sino bajo la monarquía constitucional de la estatalidad orgánica expuesta por Hegel. En este orden los privilegios no pueden ser opuestos como derechos frente al monarca, ya que éstos son particularizaciones de las diferentes ramas del trabajo, las cuales se organizan en la sociedad civil en estamentos y corporaciones, para luego articularse a través de la representación parlamentaria en el Estado. De esta manera, no quedan ya instituciones políticas por fuera de la regulación del Estado y los individuos sostienen su acción política en una eticidad apoyada en el reconocimiento y la contención ofrecida por estamentos y corporaciones. 